\title{
Arab Pre-service Teachers' Perspectives on the Role of ICT in Learning and beyond School
}

\author{
Amgad Ali Seif ${ }^{1 *}$ (1)
}

${ }^{1} \mathrm{Al}$-Qasemi Academic College of Education, ISRAEL

*Corresponding Author: amgad_seif@yahoo.com

Citation: Seif, A. A. (2020). Arab Pre-service Teachers' Perspectives on the Role of ICT in Learning and beyond School. European Journal of Interactive Multimedia and Education, 1(2), e02008. https://doi.org/10.30935/ejimed/9138

\begin{abstract}
This study was necessitated by the paucity of the data on the role of information and communication technology (ICT) in the Arab education system in Israel. The study was conducted as a cross-sectional survey among novice students from the three Arab teacher training colleges. The aim of the survey was to examine whether students' perceptions reflect the skills associated with the concepts of digital competence and higher order thinking skills (HOTS). Data were collected through the closed-item and mixed-item questionnaires. Open-ended items had also the purpose to examine participants' reasoning skills. The results of the pilot showed good internal reliability for a closed-item questionnaire $(\alpha<0.72)$ and for a mixed-item one $(\alpha<0.76)$. Both quantitative and qualitative results suggested that the majority of participants understood the relevance of ICT to their learning and other areas of life and demonstrated safe and responsible use of ICT. The findings suggested that participants were less skilled in the areas of independent learning, teamwork, and developing creativity through digital tools. The results of this survey gathered baseline information for further investigations intended to examine pre-service teachers' digital competence and develop intervention measures.
\end{abstract}

Keywords: digital competence, higher order thinking, reasoning skills, ICT, Arab pre-service teachers, Israeli education

Received: 16 May $2020 \bullet$ Accepted: 3 Aug. 2020

\section{INTRODUCTION}

The regulatory and research literature produced over the last two decades promote the idea of integrating ICT in instruction and learning processes in order to develop adaptive learning and teaching techniques (Carretero, Vuorikari, \& Punie, 2017; European Commission, 2018). An integration of ICT in school and higher education has attracted a great deal of scholarly attention over the last decades. The research reports that have appeared over the last 20 years suggest a steady growth in the adoption and use of ICT in educational institutions worldwide (Fraillon, Ainley, Schulz, Duckworth, \& Friedman, 2018). Problems, however, remain in the integration of new technologies in instruction and learning practices. There is also a belief that the role of ICT in the development of teachers' and students' HOTS has not been studied sufficiently and this area requires more investigation (Akshir Ab Kadir, 2017; Voogt \& McKenney, 2017).

The Ministry of Education of Israel embraced the initiatives proposed by the European Commission and put forth a number of policies and regulations to integrate ICT in schools. A multiple-year national ICT program ("Adapting the educational system to the 21st Century") was created to set up a framework for developing the $21^{\text {st }}$ century skills and assimilating ICT in schools (further: the ICT program) (Winer, 2018). The research on the integration of ICT in the
Israeli education system points to an increase in the use of ICT in schools and higher education institutions (Wiener, 2018). A review of the research on the use of ICT in Israeli education identified the problem of research deficiency regarding the role of new technologies in developing the Israeli Arab educational institutions and level of the digital competence of Arab teachers and students. Therefore, it was decided to undertake a number of studies in order to address this problem. The goal of the current investigation was to provide and overall picture of Arab novice pre-service teachers' perceptions of functioning in the ICT-enriched environment. The results might help identify the gaps in the implementation of the ICT-based instruction in Israeli Arab schools and outline directions for future studies.

It was widely recognized (Carretero et al., 2017; Winer, 2018) that there is a need for critical and reflective skills in the use of ICT. The theoretical background of this research project draws upon the broad concepts of digital competence and HOTS and relationship between them (see "Theoretical Framework" section). The main question investigates whether participants' perceptions reflect the knowledge and skills associated with digital competence and HOTS. To find this out, the following sub-questions were generated:

1. Which of the ICT tools are mostly used by the participants?

2. What are participants' opinions on the use of ICT in their lives in school and beyond? 


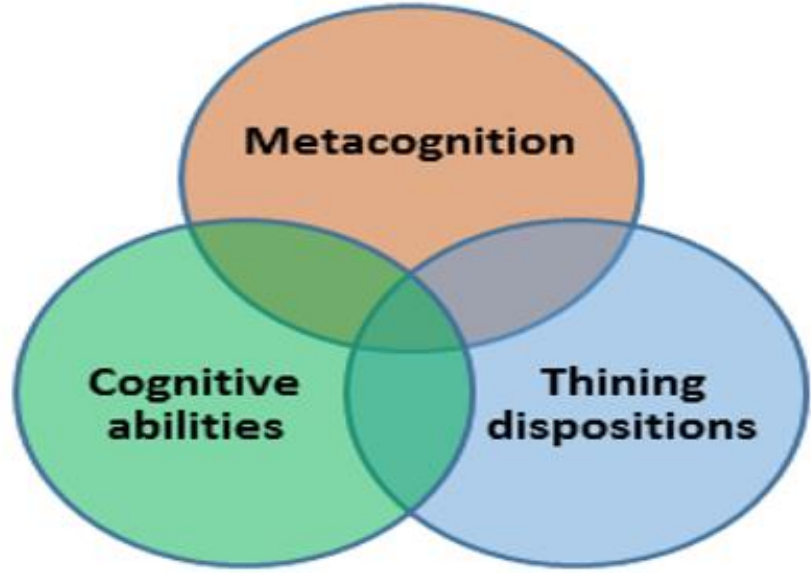

Diagram 1. Interaction of the components of HOTS

3. Do the research data suggest that participants employ HOTS in the ICT-enriched learning and real life activities?

As this group of student population consisted of the school graduates who just started their academic year in colleges, the results might give an idea of the level of digital competence they had at the beginning of their higher education studies. The construction of the instrument for measuring students' perceptions drew upon a broad concept of HOTS (see "Theoretical Framework" section), previous studies on students' HOTS (Seif, 2017; Weiss, 2010) in the Arab education sector, and digital competence (Carretero et al., 2017). A number of scales were examined to learn about measuring learners' perceptions of the work in the ICT-based learning environments (Barak \& Levenberg, 2016; Ono Academic College, n. d.). This research findings will be used for creating and refining the data collection instruments for a deeper exploration of the impact of ICT on each component of HOTS separately and in interaction with each other.

\section{THEORETICAL FRAMEWORK}

Based on the European Digital Competence Framework for Citizens (DigComp) and ICT program, the Education Ministry of Israel developed a large number of educational strategies that concern the effective use of ICT in school and higher education. The ultimate goal of the curricular reforms, which have been implemented in Israel over the last decade, is to educate independent and adaptive learners. The reforms are based on a broad conceptualisation of HOTS that encompasses cognitive, metacognitive and affective knowledge (dispositions) in order to enable students to meet the demands of the modern society. It is stated that students need to be overtly taught thinking skills across all subject matters in order to understand and process information, produce diversified points of view and solutions for problem solving, and justify solutions (Yoad, 2009). At the same time, students should develop thinking dispositions, such as inquisitiveness, self-confidence, prudence in making decisions, teamwork abilities, and other skills. Many researchers acknowledged an interrelation and interaction of cognitive, metacognitive and dispositional components of HOTS (Facione, 2011; Perkins \& Tishman, 2001). Diagram 1 illustrates that metacognition as the ability to organize and regulate cognitive processes and thinking dispositions interacts with cognitive abilities and dispositions to HOTS.
An interaction of cognitive and dispositional domains of HOTS is taking place in the new learning environment. According to the DigComp framework and ICT program in Israel, the development of students' HOTS and $21^{\text {st }}$ century skills is closely related to the enhancement of their digital competence (Carretero et al., 2017; Winer, 2018). The latter is defined as a confident, critical and creative use of ICT in educational and professional contexts. It can be seen that along with the information and data literacy, digital content creation and safety awareness, digital competence areas include such components of HOTS as cognitive skills for problem solving and thinking disposition qualities needed for communication and collaborative work (Carretero et al., 2017). The development of students' digital competence and HOTS is implemented within the context of the ICT-enriched learning environment that has the features of traditional instruction, but increasingly incorporates the technologies that change the teachinglearning interaction. A quick access to the internet, vast pool of information and technological resources is reshaping the way students acquire knowledge and skills. In the technology-based environment, teachers bear the responsibility to ensure that students understand how to use ICT tools in their learning activities and how to do this safely and responsibly.

\section{LITERATURE REVIEW}

This part of the paper deals with the publications that have appeared over about the last decade in the area of promoting digital competence in education. The review includes articles published in peer-reviewed journals, conference papers and monographs. The literature was searched through the Google Scholar search engine, ResearchGate and ERIC databases, among SSCI and SCOPUS journals, and in the Macam Gateway Services of the Mofet Institute (Israel). Two aspects are considered in the review: research into the role of ICT in the development of HOTS and an outline of the research highlighting the learning habits of Arab students in Israel.

\section{ICT and Development of HOTS}

A review of the recent journal publications on the ICT-enriched learning environment demonstrates that there is an increasing number of articles dedicated to the role of ICT in developing different aspects of HOTS (Bodily, Leary, \& West, 2019; Winer, 2018). Statistically significant correlations have been found between the length of time spent by students in the technology-rich environment and their development of computer skills and acquisition of HOTS (European Commission, 2018). Based on the data from the International Computer and Information Literacy Study (ICILS), researchers suggest a relationship between the use of ICT, self-efficacy, and student digital competence (Rohatgi, Scherer, \& Hatlevik, 2016). It is believed (Caldwell \& Heaton, 2016; Kearney \& Maher, 2019; Subran, 2013) that studying with the help of online platforms like blogs, wikis and online communities can foster cooperative learning skills, critical reflection and creativity. Baya'a, Daher, Jaber, and Anabousy (2018) hold that mobile technologies influence positively students' behavior and learning motivation and recommend to encourage preservice teachers to use them in their learning activities. The above findings also suggest that interaction between cognitive and dispositional domains of HOTS can be increased by learning new technologies. According to many researchers (Adler \& Kim, 2018; Figueiredo \& García-Peñalvo, 2017), it is helpful to expose students to the abstract, algorithmic, and logical 
Table 1. Mean scores of participants' ratings on the ICT tools used in learning

\begin{tabular}{|c|c|c|c|}
\hline $\mathbf{N}$ & ICT tools & $\mathbf{M}$ & SD \\
\hline 1 & Laptop computers. & 4.36 & 0.77 \\
\hline 2 & Mobile phones. & 4.28 & 0.76 \\
\hline 3 & Desktop computers. & 3.93 & 0.35 \\
\hline 4 & Search engines (Google). & 4.53 & 0.83 \\
\hline 5 & Online dictionaries or encyclopedias (Wikipedia). & 3.40 & 0.94 \\
\hline 6 & YouTube/other video platforms. & 3.18 & 0.98 \\
\hline 8 & Learning management systems (Moodle, Blackboard) for self-directed learning and self-assessment of learning. & 2.00 & 0.46 \\
\hline 9 & E-portfolios for self-assessment of learning performance. & 1.82 & 0.72 \\
\hline 10 & Social networks (Facebook, Instagram, Twitter). & 2.73 & 0.68 \\
\hline 11 & Messaging tools (email, chats, SMS, messaging apps). & 4.38 & 0.71 \\
\hline 12 & Online platforms like blogs and wikis to create and share information. & 1.75 & 0.85 \\
\hline 13 & MS Office applications (Word, Excel, PowerPoint). & 4.67 & 0.47 \\
\hline 15 & Software developed for studying mathematics and sciences (GeoGebra, Caber 3D). & 2.20 & 0.79 \\
\hline 16 & Professional design software and programming languages used in technical education (Visual Studio, Photoshop, AutoCAD, C Sharp, Java). & 3.93 & 0.57 \\
\hline 17 & Video-games and simulations (Moodle-based interactive simulations for science). & 1.60 & 0.69 \\
\hline
\end{tabular}

structure of computer science in order to develop problem solving skills.

At the same time, the use of new learning technologies fuels discussions over whether such technologies help or detract from the ability of the students to learn efficiently and develop HOTS. There is an opinion that investigating the links between learning and technology is a complicated process, and a relationship between technology and learning performance is rarely linear (Edwards, 2016). It was held that some of the high school students believed that in digital environment, learning skills could be affected due to the use of easy shortcuts reducing the need of reflection (Ben David-Kolikant, 2010). Bouygues (2019) claimed that insufficient evidence was found of the positive relationship between student performance on PISA and their self-reported use of ICT, and there was some evidence of a negative impact. There is a belief that learning theories lag behind technological advancements and insufficient research has been done to more critically assess the contribution of ICT to education (Edwards, 2016).

\section{A Brief Characteristic of the Learning Habits of Arab School and Tertiary Students}

It is held that the majority of the Israeli graduates that enter tertiary education, including those who choose teaching profession, are equipped with necessary ICT skills and positive attitudes towards new technologies (Pieterse, Santo, \& Grienberg, 2018; Wininger, 2018). Little data exist, however, on the level of performance of Arab students in the ICT-enriched learning environment. Of the recently conducted studies, Zidan and Ganayem (2018) and Pieterse et al. (2018) claimed that most of the Arab-speaking graduates had basic ICT skills to continue their education. Pieterse et al. (2018) argued, however, that Arab study participants required more mediation in acquiring information literacy skills than their Jewish counterparts. In the beginning of their studies, Jewish students preferred digital sources over print ones and demonstrated higher abilities of independent learning than Arab students who were more dependent on the help of instructors and librarians. A higher dependence on instructors among Arab school students was confirmed by a number of Israeli studies that explored the use of technologies in instruction and learning, level of students' inquiry and teamwork skills, and argumentation abilities (Abed \& Dori, 2013; Dkeidek, Mamlok-Naaman, \& Hofstein, 2010; Merdler \& Peled, 2016). It is claimed that this problem can be attributed (at least partially) to the fact that a teacher-centered authoritarian model of teaching in Arab schools has been historically more persistent (Seif, 2019; Wolf, 2014). It is also held that in comparison with Jewish school and tertiary students, their Arab counterparts generally experience more difficulties in understanding of words written in Latin characters, reading scientific and technical texts in Hebrew and English (Abu Asbah, 2012; Totari, 2009). Yet, a comparison of research findings presented over the last decade indicates that the differences between Arab and Jewish students are steadily decreasing with regard to Arab students' comprehension of English and use of new technologies (Wininger, 2018). This can be accounted to higher investments into the Arab education system and a better performance of Arab school students in mathematics, English and Information Technology subjects (Blass, 2019).

\section{METHODOLOGY}

\section{Research Population}

This study was conducted as a cross-sectional quantitative survey with a qualitative component. Three Arab teacher training colleges were approached with an offer to participate in the survey (a smaller percent of Arab students study teaching profession in mixed JewishArab colleges and in universities). The target population consisted of high school graduates aged 17-18 in their first year of studies. The total population sampling technique was used in order to gather enough relevant data. After obtaining the authorizations to conduct the survey, the letters were sent electronically to students to inform them in detail about the purpose and conditions of this survey. Consequently, the 323 from 327 novice students from the three colleges agreed to participate. Female respondents represented $82 \%$ of the whole research population (in Israel many Arab female school graduates choose teaching profession). Two questionnaires were delivered online by using the Google Form application.

\section{Development of Data Collection Tools}

Data were collected through the closed-item and mixed-item questionnaires. The closed questionnaire used in the current study consists of 17 items that refer to the ICT tools indicated in the regulatory documentation. In this study, the definition "ICT tools" refers to both electronic devices and software used for learning and 
other purposes (Winer, 2018). The questionnaire examines what ICT tools participants use the most in their learning activities (see Table 1). Thematically, the questionnaire is structured as follows: electronic devices (items 1-3); services for locating and retrieval of data (4-7); tools for self-assessment of learning $(8,9)$; tools for teacher-student and peer communication and collaboration in implementing assignments (1012); desktop and online software to store, process and present data (1316); and video-games and simulations (17). Respondents rated their use of each tool on a five-point Likert scale, from "never" (1) to "very frequently" (5). A mixed-item questionnaire consists of 22 items (20 close-ended and 2 open-ended items) designed to identify the role of ICT in participants' lives and examine whether participants employ HOTS when functioning in the ICT-enriched learning environment and beyond school. Participants' perceptions were measured on a fivepoint Likert-type scale, from "strongly disagree" (1) to "strongly agree" (5).

Based on the scales developed by Weiss (2010) and Seif (2017), the mixed-item questionnaire designed for this study measured two variables related to the cognitive and dispositional domains of HOTS. In the questionnaire section containing closed items, each variable includes a number of categories that refer to the employment of HOTS in the ICT-enriched learning environment and beyond school:

Cognitive and metacognitive dimensions of HOTS:

- organization and management of learning activities with the help of ICT tools;

- abilities to employ search strategies to locate, retrieve, and evaluate digital information;

- self-assessment of learning through the use of e-portfolios and learning management systems in order to critically analyze learning achievements and set learning goals;

- demonstration of problem solving skills at studying core curriculum subjects and in technical education;

- application of the digital knowledge and skills acquired in school to everyday situations (skill transferability).

Dispositional dimensions of HOTS:

- learning motivation and self-confidence in the ICT-enriched environment;

- demonstration of the self-directed learning abilities through the use of learning management systems;

- creation of the new and interesting content with the help of ICT tools, including blogs and wikis;

- demonstration of the team work abilities by using web-based tools (messaging services, blogs, wikis, and social networks);

- demonstration of responsibility in the use of ICT tools (personal safety on the web, legal responsibility; awareness of the health risks from electronic devices).

The open-ended statements were developed to obtain qualitative data. These might provide more complete characteristics of the cognitive and dispositional aspects of participants' thinking (Ku, 2009). It should be emphasized that the existing questionnaires for measuring digital competence have a closed-item format while the use of openended questions might contribute to the issues that quantitative data alone cannot reveal. With the help of open-ended statements, the purpose was to provide more information about the cognitive domain of participants' HOTS reflected in their abilities to substantiate opinions by providing reasons and examples. The cover letter attached to the questionnaire contained an explanation of how responses should be constructed. Following the principles behind the drills included in the recommendations by the Ministry of Education (Yoad, 2009; section on developing students' reasoning skills), the first open-ended item represented an assertion ("It is important to increase the knowledge of ICT both in learning and beyond school”) that participants should support or refute by using arguments/examples based on established facts. The same requirement concerned another open-ended statement that included the demand to describe how participants employed their knowledge of ICT tools and their digital skills in learning practices and everyday activities. Both open-ended items were expected to provide an ample amount of qualitative data that might indicate whether participants employed HOTS in the use of ICT tools

In order to assess the content reliability of both questionnaires, two college lecturers (so called "critical friends"), who were well-acquainted with the HOTS-related research and ICT, examined questionnaires' items for their consistency with the above areas. The internal consistency reliability of questionnaires' items was examined by using Cronbach's coefficient alpha. Both closed-item and mixed-item questionnaires were validated through pilot testing among nonparticipant novice student teachers. The pre-test results showed that both instruments had the internal consistency reliability of $\alpha<0.72$ and $\alpha<0.76$ respectively, which can be considered good (Taber, 2018).

\section{Analysis of Data}

The data collected through closed-ended items were analysed by using IBM SPSS (version 23.0) software which is widely employed in the statistical analysis of social science data. For the analysis of participants' responses to open-ended questions, thematic analysis was used. A triangulation of quantitative and qualitative results was carried out in order to create a more reliable basis for research inferences.

The method of thematic analysis has been chosen as a flexible research tool that can describe the data in rich detail and can be used within different theoretical frameworks (Braun \& Clarke, 2006). For the process of coding, simple sentences (either standalone sentences or as subordinate clauses) were treated as "meaningful, manageable chunks" of data used in analysis (Webster-Wright, 2010, p. 90). Both inductive and deductive coding techniques were employed, with the latter based on the concepts of HOTS and digital competence. Coding was carried out iteratively. Some of the segments of data were coded with more than one code and were the source for more than one theme (Hardy \& Bryman, 2004). Codes were grouped into themes/categories which were combined or split up to form main themes. The theme prevalence was determined by the percentage of responses from which a theme was developed. At the same time, significance of a theme was not necessarily dependent on quantifiable measures (Braun \& Clarke, 2006), but whether it was of relevance to the issues examined (see "Discussion" section, paragraph 5).

\section{Study Limitations and Measures to Address Them}

In what follows, noteworthy limitations of this study are described, as are the measures to minimize them. In this survey, questionnaires measured participants' perceptions of their knowledge and skills in the area of technology-based education, but not the level of knowledge and skills directly. Respondents might fail to assess themselves properly, and there is a possibility of a socially desirable response (Lavrakas, 2008). In order to obtain more evidence and deeper insight in participants 
Table 2. Mean scores of participants' perceptions of their use of ICT tools

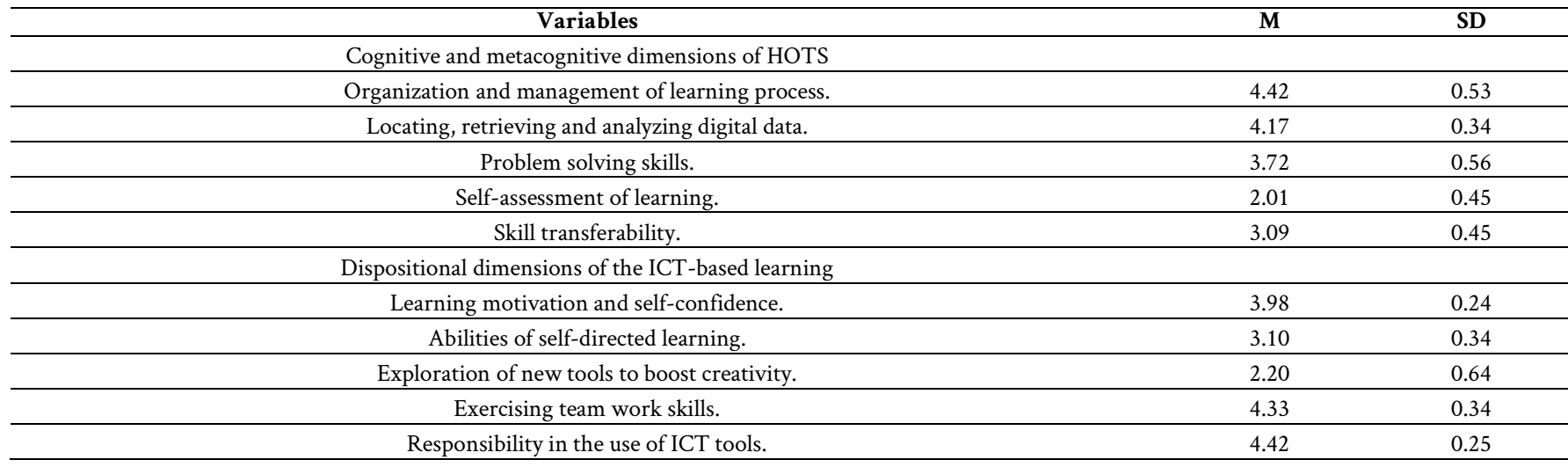

learning attitudes and habits, open-ended items were designed to provide an ample amount of qualitative data that were triangulated with quantitative results. To increase the content reliability of this study, a large amount of literature was reviewed, including official documents and research on digital competence and HOTS. In order to enhance the interpretive validity, findings included many verbatim accounts of what people said (Silverman, 2013). The theoretical validity of inferences was enhanced by the concepts presented in the relevant research literature. Almost all the novice students of the three Arab teaching colleges participated in the study, which made the survey sample more representative of this kind of student population in Israel.

\section{FINDINGS}

\section{Results of Statistical Analysis}

This section presents the results of statistical analysis of the data collected through questionnaires' closed items. Table 1 shows participants' ratings of their use of ICT tools included in the closed questionnaire.

The tools are listed in the order they are presented in the questionnaire. The names in parentheses serve as examples of the ICT tools included in the ICT program. The results indicated that laptop computers occupied the first place among the electronic devices used for learning purposes (4.36) and the use of mobile phones is also highly rated (4.28). Among the interactive web services (items 4-7), search engines ranked first with a high mean score of 4.53 , followed by mean score of 4.15 for learning portals. In the category referring to the communication of data for learning purposes and collaboration (10-12), messaging applications garnered the highest mean score of 4.38. Blogs and wikis got low means (1.60 and 1.75 respectively), which suggested a relatively low use of these tools in Israeli Arab schools. The same might be true for the use of e-portfolios and learning management systems $(8,9)$ for the self-assessment of learning (2.00 and 1.82 respectively), although they were included in the ICT Program as an effective tool for developing the independent learning skills. Among the software for storing, processing and presenting the data (13-16), desktop MS Office applications were at the first place (4.67), which suggested that they were highly used for implementing a variety of learning assignments, while cloud-based services were less used (3.42). The software employed in technical education received higher score (3.93) than the software for mathematics and sciences included in the ICT program (2.20). Learning through video games and simulations had very low mean score (1.60) suggesting an insignificant role of these tools in participants' learning practices.
In Table 2, there are mean scores of the variables generated from the closed items of the mixed-item questionnaire.

The results showed that with regard to the cognitive domain of HOTS, participants highly rated their capacity to organize and manage learning activities through the use of ICT tools, as evidenced by the mean score of (4.42). This suggests that participants have metacognitive skills for organizing and implementing their learning activities.

At the same time, self-assessment of learning, which was important to demonstrate the metacognitive abilities to control learning processes, received low score (2.01). Participants believed that they had strong skills for locating and processing digital data (4.17). Problem solving skills also received good results (3.72). As to the dispositional domain of HOTS, the highest mean score belongs to participants' awareness of the safe and responsible use of ICT (4.42). This score is followed by the mean score of 4.33 (team work abilities) that suggests good skills for collaborative work. The abilities of independent learning assisted by ICT tools received modest characteristic (3.10), and the mean score related to creativity was low (2.20). The statistical results, however, provide incomplete information on participants' learning habits and attitudes regarding the use of ICT tools. Final inferences are made after the triangulation of quantitative and qualitative findings.

\section{Results of the Analysis of the Responses to Open-ended} Statements

The results of analyzing the responses to open-ended statements are presented from the two aspects: compliance with the requirement to provide arguments/examples to support opinions and results of thematic analysis.

About $6 \%$ of all the participants composed their responses to both statements by using single sentences: "Knowledge of ICT is necessary to complete school assignments" or "The use of smartphone helps me in my learning". The large majority (around 94\%) of the participants provided ample responses containing two more sentences, although not all of them met the requirements as to the form and content of response. Almost $26 \%$ of them wrote two more claims, with no backing information: "ICT tools helped me in learning. They are also useful for everyday tasks". The rest of the respondents complied with the instructions: "Improving the knowledge of ICT is necessary. Statistics shows that our competitiveness on the job market depends on our proficiency in technologies. Today, we perform many operations online" or "The internet helps me a lot in my life. For example, I like searching around on forums because people sometimes offer good solutions or interesting ideas." 
Table 3. Main theme 1. Role of ICT in the society and personal development

\begin{tabular}{lcc}
\hline $\mathbf{N}$ & Sub-themes & Q uotations \\
\hline 1 & Impact of ICT globally. & Today, any country in the world cannot advance without using new technologies. Almost daily the media \\
announce new advances in ICT.
\end{tabular}

Table 4. Main theme 2. Role of ICT in facilitating the process of learning

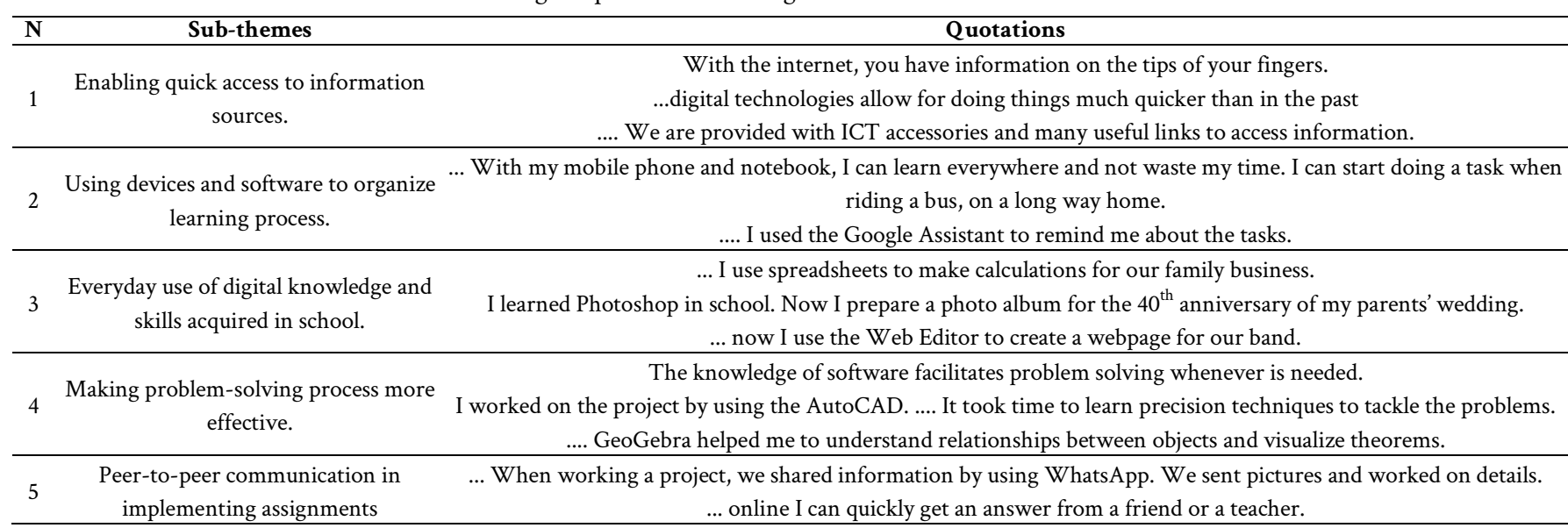

Table 5. Main theme 3. Safe and responsible use of ICT

\begin{tabular}{ccc}
\hline $\mathrm{N}$ & Sub-themes & Q uotations \\
\hline 1 & Maintaining security on the web. & It is very important to be an informed user. Tragedies happen because people do not learn about how to properly \\
behave on the web.
\end{tabular}

As a result of thematic analysis of participants' responses, five main themes were generated. Both main and sub-themes are listed in descending order in Tables 3-7, according to the theme prevalence, and are illustrated by quotations. Ellipses indicate the omission of part of a quotation that is not related to the theme.

At the top of the list (70\%), there is a theme that refers to participants' awareness of ICT as a driving force both for the socioeconomic development worldwide and personal growth, and the necessity of the ICT-based education for the prosperity of the Arab communities in Israel (Table 3).

The second dominating theme (65\%) relates to various aspects of organizing and managing the process of learning and applying the knowledge learned in school in real life contexts (Table 4). The most salient component refers to having the needed data at one's fingertips and tasks being done quickly while there was no description of the use of search strategies. It was acknowledged that ICT tools assisted to organize learning and the skills acquired in school were helpful in everyday life. In addressing the issue of problem solving, the examples illustrating the use of software in technical education received more attention than the use of software for studying mathematics and sciences. Very few respondents noticed the game-based problem solving learning activities practiced in the junior high school and characterized as a "big fun". There were vague descriptions of collaborative work.
The notions like "brainstorming" or "online peer discussion of a problem" were nearly absent, but there were many examples of soliciting assistance from more competent persons, and some examples of communication on non-learning issues through social networks. There were almost no records illustrating the use of web-based platforms like blogs and wikis, and there were no data on using ICT in the self-assessment of learning.

Another salient theme (58\%) refers to participants' beliefs about the legal, ethical and physical aspects of employing ICT in school and beyond (Table 5). The data concerning these issues demonstrated that participants were aware of the responsible and safe use of ICT.

About the third of responses (34\%) concerned the skills needed for independent and creative learning (Table 6).

With regard to these issues, there was the least number of specific examples to support participants' assertions, in comparison with other themes. The large majority of the statements were of general character and they provided little information about the specific use of ICT tools to demonstrate participants' independent thinking abilities and creativity. Also, there were complaints regarding an overloaded curriculum and lack of time for information search and exploration of new technologies.

A small number of responses (6\%) showed that there were participants to whom ICT were of little relevance to their daily activities (Table 7). The belief was expressed that having the most basic 
Table 6. Main theme 4. The importance of ICT in developing the independent and creative learning skills

\begin{tabular}{lcc}
\hline $\mathrm{N}$ & Sub-themes & Q uotations \\
\hline 1 & $\begin{array}{c}\text { ICT tools for increasing learning } \\
\text { motivation and self-confidence. }\end{array}$ & $\begin{array}{c}\text { I believe that the use of ICT can boost the motivation to learn. } \\
\text { When I learn more about some software, I feel more confident and satisfied. }\end{array}$ \\
\hline 2 & Improving thinking skills. & $\begin{array}{c}\text { Learning about ICT helps to work independently and improves thinking. } \\
\text {... Learning about new software is also good for thinking skills. }\end{array}$ \\
\hline 3 & The wish to learn new technologies. & .... I learned these applications by myself. It's a shame we do not use them in school. \\
\hline 4 & Fostering creativity through ICT tools. & The use of ICT tools enables creative learning. \\
\hline & Lack of time to increase digital skills & $\begin{array}{c}\text { School curriculum is overloaded and there are many assignments to do at home. There is little time to engage in } \\
\text { searches and learn much about technologies. }\end{array}$ \\
\hline
\end{tabular}

Table 7. Main theme 5. Reducing the importance of ICT for learning and everyday life

\begin{tabular}{|c|c|c|}
\hline $\mathrm{N}$ & Sub-themes & Quotations \\
\hline & The need of having the most basic ICT skills. & $\begin{array}{l}\text {... Technologies are quickly getting outdated, it is useless to constantly rush to learn new ones. } \\
\text {... For many people, the basic knowledge of ICT would be sufficient. }\end{array}$ \\
\hline & $\begin{array}{l}\text { Showing more interest in physical activities } \\
\text { and family life than in learning about ICT. }\end{array}$ & $\begin{array}{l}\text { I prefer to devote my spare time to surfing than to learning more about new technologies. } \\
\text {.... Family values are more important. Our grandparents enjoyed spending time together and listening to each } \\
\text { other without using the internet and other technologies. }\end{array}$ \\
\hline
\end{tabular}

knowledge of technologies would be sufficient to function well in life. A problem was pointed out that new technologies made little contribution to the quality of communication between people.

The themes described in this section shed light on participants understanding of the relevance of ICT to their learning and other activities by showing why and how ICT tools were used. In the next section, qualitative findings will be compared with quantitative results in order to make research inferences.

\section{DISCUSSION AND CONCLUSION}

The results of this survey showed that the majority of participants complied with the requirements to provide arguments/examples to back up their opinions. Those who wrote short responses in generalities or sweeping claims could be unmotivated to participate in the study, but as novice students, they were unwilling to show this to the college authorities. Possibly, some of the respondents believed that their assertions were quite convincing, or perhaps they were unable to substantiate their opinions. Whatever the reason, more than $30 \%$ of all the responses did not demonstrate reasoning skills as it was required in the questionnaire. The abilities of reasoning and presenting information in a clear way are considered important components of HOTS (Yoad, 2009) and are of vital importance for teachers to deliver knowledge to learners.

According to both quantitative and qualitative results, the schools, in which participants had learned before they entered the colleges, were supportive of the technology-based learning. The quantitative and qualitative findings converge to indicate that electronic devices and a wide range of software applications were widely employed to organize and manage learning and other activities. This corresponds to the recommendations on the use of electronic devices and software in Israeli schools (Ran, 2018). At the same time, cloud-based services for storing and processing the data were less used than desktop applications, and there was little evidence of the learning based on games and simulations. Digital tools for the self-assessment of learning and self-directed learning were barely used. Messaging applications and social networks were not fully employed in the teamwork learning. According to the quantitative and qualitative results, there was a very little use of popular collaboration platforms like blogs and wikis, although these tools were recommended by researchers (Winer, 2018) and indicated in the Ministry of Education's guidelines (Ran, 2018).

The quantitative and qualitative results suggested that participants had the metacognitive abilities to organize and plan their work on school assignments and other activities with the help of ICT. Responses showed that problem solving was aided by ICT tools in various areas, with an emphasis made on the use of technologies to deal with specific aspects of technical problems. Participants acknowledged a relationship between the learning of ICT (cognitive processes) and increasing selfefficacy, motivation and creativity, which was also suggested by many researchers (Rohatgi, Scherer \& Hatlevik, 2016; Subran, 2013). These data suggest an interaction between different components of HOTS (see Diagram 1) increased by learning the new technologies. The knowledge and skills learned in school were considered of practical usefulness for problem solving tasks in everyday contexts, which was confirmed by other studies (Baya'a et al., 2018). Both quantitative and qualitative findings showed participants' awareness of the safe and responsible use of ICT. In comparison with the earlier data on the comprehension of English by Arab students (Abu-Asbah, 2012), this study's findings did not show that participants had difficulties in understanding texts in English.

Yet, there are several areas of concern with regard to some of the data. Both quantitative and qualitative findings showed that participants assessed themselves as having good skills to locate, retrieve and evaluate digital information. These beliefs could be misplaced. In the cover letter to the questionnaires, the respondents were required to provide the examples of how they used ICT tools, including the strategies for searching digital data. There were many responses stating that the use of internet allowed students to get digital information quickly and easily, but there were no qualitative data on the use of information search strategies. In addition, some of the participants mentioned an overloaded syllabus which left little time for information search and improvement of their knowledge of ICT. All these facts allow for an assumption that instead of doing the search by themselves, the majority of respondents were heavily assisted by their instructors in getting the needed information. This assumption can be supported by the research showing that in comparison with Jewish students, their Arab counterparts require more mediation in the dimensions of 
information literacy (Pieterce et al., 2018) and in independent inquiry (Abed \& Dori, 2013). There are also exist unhealthy school policies to achieve good results by all means instead of making students work independently and improve their thinking skills (Seif, 2019).

Furthermore, the quantitative results from both questionnaires demonstrated that participants highly evaluated their own skills at collaborative work implemented through the use of messaging services. But the qualitative data did not suggest the understanding of the principles of teamwork, and there were many examples of communication in order to seek answers from more competent peers. Both quantitative and qualitative findings showed low results for selfdirected learning with the help of ICT tools. There was little involvement in the self-assessment of learning which was not reflected in qualitative data. A number of participants - albeit a relatively small one - did not consider ICT of a big importance to their lives, which might be due to the failure of their instructors to teach these students how to effectively use ICT tools. This could be an example of how little amount of data could contribute to the understanding of a serious problem (Braun \& Clarke, 2006). A considerable amount of the sweeping claims, which emphasized the great importance of ICT for learning motivation and self-confidence and for improvement of thinking skills and creativity, could be explained by participants' wish to present themselves in the best possible light (Lavrakas, 2008). In fact, qualitative data that concerned independent learning skills and creativity in thinking suggested that participants had insufficient skills in these areas.

It was stated that the results of this survey were expected to provide the baseline information for further investigations and outline the goals which need immediate attention. The results suggested that study's participants had the knowledge and skills to study in colleges, but a lot of work should be done to achieve the level of digital competence and HOTS required for teachers. Scales should be developed in order to measure students' independent learning skills, including the construction and use of information search strategies, and students' assessment of their own learning process. There is a need to test how students exercise their abilities of collaborative learning and creativity by using Web-based platforms. The reasoning skill drills and argument mapping software can be used to test and develop learners' argumentation skills. There is a need for further research that will examine an integration of ICT in Israeli Arab schools and relationship between the use of technologies and development of HOTS. It is imperative that future teachers have competence and confidence in the use of ICT and the awareness of how technology can be employed to transform instruction.

\section{REFERENCES}

Abed, A., \& Dori, Y. J. (2013). Inquiry, chemistry understanding levels, and bilingual learning. Educación Química, 24(1), 37-43. https://doi.org/10.1016/S0187-893X(13)73193-8

Abu-Asbah, K. (2012). The Arab education in Israel: Dilemmas of a national minority. Jerusalem: The Floersheimer Institute for Policy Studies.

Adler, R. F., \& Kim, H. (2018). Enhancing future K-8 teachers' computational thinking skills through modeling and simulations. Education and Information Technologies, 3(4), 1501-1514. https://doi.org/10.1007/s10639-017-9675-1
Akshir Ab Kadir, M. (2017). What Teacher Knowledge Matters in Effectively Developing Critical Thinkers in the 21st Century Curriculum? Thinking Skills and Creativity, 23, 79-90 https://doi.org/10.1016/j.tsc.2016.10.011

Barak, M., \& Levenberg, A. (2016). Flexible: An individual differences thinking in learning measure for learning in technology-enhanced environments. Computers \& Education, 99, 39-52. https://doi.org/10.1016/j.compedu.2016.04.003

Baya'a, N., Daher, W., Jaber, O., \& Anabousy, A. (2018). Educating preservice teachers in metacognitive activities. In H. J. Weigand, A. Clark-Wilson, \& A. Donevska-Todorova (Eds.), Proceedings of the Fifth ERME Topic Conference - Mathematics Education in the Digital Age MEDA (pp. 35-43). Copenhagen: University of Copenhagen.

Ben David-Kolikant, Y. (2010). Digital natives, better learners? Students' beliefs about how the internet influenced their ability to learn. Computers in Human Behavior, 26(6), 1384-1391. https://doi.org/10.1016/j.chb.2010.04.012

Blass, N. (2019). A glance at the education system. Jerusalem: Taub Center for Social Policy Studies in Israel. [Hebrew].

Bodily, R., Leary, H., \& West, R. E. (2019). Research trends in instructional design and technology journals. British Journal of Educational Technology, 50(1), 64-79. https://doi.org/10.1111/ bjet.12712

Bouygues, H. L. (2019). Does educational technology help students learn? Retrieved from: https://reboot-foundation.org/wp-content/ uploads/_docs/ED_TECH_ANALYSIS.pdf

Braun, V., \& Clarke, V. (2012). Thematic analysis. In H. Cooper, P. M. Camic, D. L. Long, A. T. Panter, D. Rindskopf, \& K. J. Sher (Eds.), APA handbook of research methods in psychology, Vol. 2, (pp. 57-71). American Psychological Association.

Caldwell, H., \& Heaton, R. (2016). The interdisciplinary use of blogs and online communities in teacher education. International Journal of Information and Learning Technology, 33(3), 142-158. https://doi.org/10.1108/IJILT-01-2016-0006

Carretero, S., Vuorikari, R., \& Punie, Y. (2017). DigComp 2.1: The Digital Competence Framework for Citizens with eight proficiency levels and examples of use. Luxembourg: Publications Office of the European Union.

Dkeidek, I., Mamlok-Naaman, R., \& Hofstein, A. (2010). Effect of culture on high school students' question-asking ability resulting from an inquiry-oriented chemistry laboratory. International Journal of Science and Mathematics Education, 9(6), 1305-1331. https://doi.org/10.1007/s10763-010-9261-0

Edwards, L. (2016, November-December). Education, technology and higher order thinking skills. Paper presented at the Australian Association for Research in Education (AARE) Conference. Melbourne, Victoria.

European Commission (2018). Commission staff working document Proposal for a council recommendation on key competences for lifelong learning. Retrieved from: https://eur-lex.europa.eu/legal-content/ $\mathrm{EN} / \mathrm{TXT} / \mathrm{PDF} /$ ?uri=CELEX:52018SC0014\&from $=\mathrm{EN}$

Facione, P. A. (2011) Think critically. Englewood Cliffs, NJ: Pearson Education. 
Figueiredo, J., \& García-Peñalvo, F. J. (2017). Improving computational thinking using follow and give instructions. In J. M. Dodero, M. S. I. Sáiz, \& I. R. Rube (Eds.), Proceedings of the 5th International Conference on Technological Ecosystems for Enhancing Multiculturality (TEEM 2017) (pp.1-7), New York, NY: ACM.

Fraillon, J., Ainley, J., Schulz, W., Duckworth, D., \& Friedman, T. (2018). IEA International Computer and Information Literacy Study 2018 Assessment Framework. Amsterdam: Springer Open.

Hardy, M., \& Bryman, A. (2004). Handbook of data analysis. London: Thousand Oaks.

Kearney, M., \& Maher, D. (2019). Mobile learning in pre-service teacher education: Examining the use of professional learning networks. Australasian Journal of Educational Technology, 35(1), 135148. https://doi.org/10.14742/ajet.4073

$\mathrm{Ku}, \mathrm{K}$. Y. L. (2009). Assessing students' critical thinking performance: urging for measurements using multi-response format. Thinking Skills and Creativity, 4(1), 70-76. https://doi.org/10.1016/ j.tsc.2009.02.001

Lavrakas, P. J. (2008). Encyclopedia of survey research methods. Thousand Oaks, CA: Sage Publications.

Merdler, M., \& Peled, Y. (2016). Tendencies and preferences of choosing information sources in academic learning: A Case of native Hebrew and native Arabic speakers in Israel. Journal of Educational and Social Research, 6(1), 39-47. https://doi.org/10.5901/jesr.2016.v6n1p39

Ono Academic College (n.d.). A questionnaire for examining students' opinions on learning in the technology-based constructivist environment. Retrieved from: https://sites.google.com/site/mla seminarproject/quest [Hebrew].

Perkins. D. N., \& Tishman, S. (2001). Dispositional aspects of intelligence. In S. Messick, \& J. M. Collis (Eds.), Intelligence and personality: Bridging the gap in theory and measurement (pp. 233-257). Maweh, NJ: Erlbaum.

Pieterse, E., Santo, Z., \& Grinberg, R. (2018). A multicultural approach to digital information literacy skills evaluation in an Israeli college. In: Y. Eshet-Alkalai, I. Blau, A., Caspi, N. Geri, \& Y. Kalman (Eds.), Proceedings of the $18^{\text {th }}$ Chais Conference for the Study of Innovation and Learning Technologies: Learning in the Technological Era (pp. 174183). Raanana: The Open University of Israel. [Hebrew].

Ran, E. (2018). Desirable changes of learning materials in the education system in the 21st century. Tel-Aviv: The Mofet Institute. [Hebrew].

Rohatgi, A., Scherer, R., \& Hatlevik, O. E. (2016). The role of ICT selfefficacy for students' ICT use and their achievement in a computer and information literacy test. Computers $\mathcal{E}$ Education, 102(1), 103116. https://doi.org/10.1016/j.compedu.2016.08.001
Seif, A. (2017). Developing higher order thinking skills of Arab high school students in Israel (Doctoral dissertation). University of Derby, Derby, UK. Retrieved from http://derby.openrepository.com/ derby/handle/10545/621587

Seif, A. (2019). Integration of higher order thinking skills into the Arab education system in Israel: a general perspective. Italian Journal of Sociology of Education, 11(3), 304-326. https://doi.org/10.14658/ pupj-ijse-2019-3-17

Silverman, D. (2013). Doing qualitative research: a practical handbook. London: Sage.

Subran, D. (2013, April). Developing higher-order thinking with ICT. Paper presented at the Biennial Conference of the University of the West Indies Schools of Education. Augustine, Trinidad and Tobago.

Taber, K. S. (2018). The use of Cronbach's Alpha when developing and reporting research instruments in science education. Research in Science Education, 48(6), 1273-1296. https://doi.org/10.1007/ s11165-016-9602-2

Totari, M. (2009). The needs of Arab students in teacher training college and level of their adaptation to academic life. Kiryat Tivon: Oranim Teacher College. [Hebrew].

Voogt, J., \& McKenney, S. (2017). TPACK in teacher education: are we preparing teachers to use technology for early literacy? Technology, Pedagogy and Education, 26(1), 69-83. https://doi.org/10.1080/ 1475939X.2016.1174730

Webster-W right, A. (2010). Making a difference through learning at work: Authentic professional learning. London, New York: Springer.

Weiss, R. (2010). A study of processes leading to the practical and professional development for critical thinking skills among B. A. students of business administration (Doctoral dissertation). University of Derby, Derby, UK. Retrieved from http://derby.openrepository. com/derby/handle/10545/621587

Winer, D. (2018). Israel: country report on ICT in education. Brussels: European Schoolnet (EUN).

Wininger, A. (2018). The Arab education at a glance. Jerusalem: The Knesset. The Information and Research Center. [Hebrew].

Wolf, L. (2014). Learning assessments in Israeli's schools: Beyond controversy and towards best practice. Washington DC: GIIS-The Gildenhorn Institute for Israel Studies, University of Maryland.

Yoad, T. (Ed.) (2009). Higher order thinking strategies: guiding document for national and local curriculum planners and for developers of learning resources. Jerusalem: Ministry of Education, Pedagogical Secretary, Division for Planning and Development of Curricula. [Hebrew].

Zidan, W.S., \& Ganayem, A. N. (2018). Technology, education and cultural differences. Tel Aviv: The Mofet Institute. [Hebrew]. 